The Review of Finance and Banking

print ISSN 2067-2713, online ISSN 2067-3825

Volume 11, Issue 2, Year 2019

http://dx.doi.org/10.24818/rfb.19.11.02.03, Pages 79-90

\title{
DOES IPO GRADING IMPACT PRICE EFFICIENCY IN INDIA?
}

\author{
KEDAR MUKUND PHADKE AND MANOJ S KAMAT
}

\begin{abstract}
Securities and Exchange Board of India (SEBI) launched compulsory grading of IPOs in May-2007. The listing day and long-run performance of IPOs are analyzed to examine the effects of IPO certification among underpriced graded IPOs listed in India listed between fiscal years 2006 and 2013. Using a sample of 114 underpriced graded IPOs, this study reveals that (1) the effects of certification are demonstrated with higher-grade IPOs underpriced the least, (2) certification effects do not continue to persist over the long run, and (3) Price corrections are extreme over the long run with lower grade IPOs.
\end{abstract}

\section{INTRODUCTION}

Compulsory grading of "Initial Public Offerings (IPO)" was announced by Securities and Exchange Board of India (SEBI) in May-2007 (made non-obligatory by SEBI from Feb-2014) to lessen information asymmetry and to make supplementary information available concerning unlisted firms or those with no performance history. This action was aimed to aid retail investors to evaluate the issue before investing. Listing firms use certification tools to minimise the information symmetry between retail and institutional investors to entice investors to an IPO issue. A SEBI-certified rating agency specifies an IPO a grade on a 5-point range with a higher grade suggesting better fundamentals of the issuing firm. Smaller sized firms with a poor track record are very likely to get lower grades.

SEBI has laid substantial stress on improving disclosure and transparency concerning listing firms to aid the investor community. Grading of IPOs was introduced to equip the retail investor specifically. Although mandatory grading of IPOs was abolished post-Feb-2014, it is critical to examine if IPOs during the obligatory period helped in reducing underpricing and information asymmetry. If grading does decrease the extent of underpricing, issuing firms should consider voluntary grading of their issues. Although the issue cost would increase in the case of optional grading, it is a critical point to consider since decreased underpricing would aid firms to raise more capital. Since the IPO grade reflects the firm's fundamentals, it is of importance to identify if the long-run performance of graded IPOs could be predicted with the assigned grades at the time of issuance. For the factors mentioned above, this investigation provides an insight into the listing day and long-run performance of graded IPOs in India which is of interest for academicians and practitioners.

The 'Certification effect' is a firm-specific factor relevant to cases when a venture-capitalbacked firm decides to go public. Literature acknowledges lower underpricing of IPOs of firms that came with support from venture-backed firms of good credibility and reputation (Barry 1990, Megginson 1991). The underwriter's reputation can also offer a certification effect. A higher grade assigned by IPO rating-firms indicates strong fundamentals of the issuing firm and

Received by the editors June 25, 2019. Accepted by the editors October 18, 2019.

Keywords: IPO, Grading, BHAR, MAARO, Event Study.

JEL Classification: G12, G14, G15, G18.

Kedar Mukund Phadke, Assistant Professor, National Institute of Construction Management \& Research (NICMAR), Goa, India. E-mail: kphadke@yahoo.com.

Manoj S Kamat, PhD, Principal, Shree Mallikarjun College, Goa, India. E-mail: mskamat@gmail.com.

This paper is in final form and no version of it will be submitted for publication elsewhere. 
vice-versa. The certification effect is tested here in this study to examine the influence of IPO grades on listing day performance. Furthermore, this research study examines if the benefits of certification continue to persist over the long-run for graded IPOs.

This study is based on earlier research studies related to IPO underpricing in India and the effects of grading on IPO underpricing such as Poudyal (2008); Deb and Marisetty (2010); Khurshed, Pande, Vismara, and Paleari (2014); Jacob and Agarwalla (2015); Sahoo (2016); Dhamija and Arora (2014) and Dhamija and Arora (2017a). This particular research study differs from the studies acknowledged for the following factors (1) this study covers the entire period when grading of IPOs was obligatory, (2) the study sample omits small and medium enterprise to negate any impact of small issue sizes. Furthermore, this study leaves out any follow-on public offerings because such offerings tend to decrease the average level of underpricing, and (3) The study employs two measures of long-run performance for the robustness of tests.

The motivation to write this paper is two-fold. First, it is essential to determine if a higher graded IPO implies superior firm quality resulting in lower underpricing. If that is true, the IPO grades serve as a certification mechanism. Second, it is important to determine if higher-grade IPOs perform better than lower-grade IPOs in the long-run. If that is true, it would mean that the effects of certification last over the longer term. This study analyses the listing day and the long-run performance of underpriced graded IPOs in India. Subsequently, the goals of this study are:

1. To examine the extent of underpricing based upon their listing day performance, and

2. To examine the long-run performance of graded IPOs in India at selected intervals.

The contributions of the study are (1) effects of certification appear with lower grade IPOs underpriced the most, (2) the assigned grades do not give an explanation of the long-run performance of graded IPOs, and, effects of certification do not last over the long term, and (3) Price corrections are extreme over the long run with lower grade IPOs.

This study is further arranged as follows. The introduction is followed by a review of literature in Section 2, testable hypothesis in Section 3, data and methodology in Section 4, results and discussion in Section 5. Lastly, the summary and conclusions are covered in Section 6.

\section{Literature Review}

In the absence of IPO grading, certifications on the quality of an IPO by investment bank(s) play a critical role. Chemmanur and Fulghieri (1994) put forward a model that puts the responsibility on banks via its credibility to build trust within investors on issues marketed by the bank. Good bank credibility and reputation indicate better IPO quality. However, Allen and Faulhaber (1989); Grinblatt and Hwang (1989); Welch (1989); Chemmanur (1993) advocate that towards attracting more investors to a high-quality IPO issue, underpricing should be more substantial. This course of action would drive low-quality issues out consequently. The study by Beatty and Ritter (1986) propose that bankers need to create an equilibrium such that they underprice an issue enough to bring in investors but not as much to lose their clients, i.e., the issuers. Titman and Trueman (1986) suggest that issuing firms with a good track record would choose reputable banks and underwriters. The issuing firms demonstrate value by their choice of banks and underwriters. Maksimovic and Unal (1993) identify that the offer price and underwriter reputation have considerable explanatory power in anticipating after-market price performance. Carter, Dark, and Singh (1998) find that underpricing is less when it comes to issues handled by reputable institutions. In essence, investors consider underwriting by prominent bankers as a certification mechanism.

From previous studies outside India, not only is underpricing lower but the performance of IPOs both in the short and long-run seems to get better for issues underwritten by reputable underwriters although evidence on this is mixed. Chan and Lo (2011) find that issuers that obtain a credit rating before an IPO issue are less underpriced than other issuers. An evaluation of the extant literature suggests that underpricing can vary based upon the status of the 
underlying certification mechanism used. The IPO grading technique embraced by SEBI was a measure to solve the complexity dealt with by retail investors regarding the IPO quality by having listing firms employ the services of rating agencies to grade their IPO issue.

The evidence on the effects of IPO grading on underpricing and the long-run performance is mixed in India. Whereas Khurshed et al. (2014); Jacob and Agarwalla (2015); Dhamija and Arora (2017a) find no effects of certification on underpricing, other studies for example, Poudyal (2008); Deb and Marisetty (2010); Sahoo (2016) find the effects of certification credible since they all witness reduced underpricing with higher grades. In regards to long-run performance, Poudyal (2008) finds out that higher graded IPOs perform better over 30-days. Deb and Marisetty (2010) find that long-run performance of graded IPOs is the same regardless of the IPO grade and lastly Dhamija and Arora (2014) document that lower grade IPOs perform better over the long term.

Poudyal (2008) examined the efficiency of IPO grading using a sample of 63 IPOs listed in India in between 2005-2008. The first facet from the author's study reviewed underpricing as a function of the IPO grade, subscription rate, firm age, issue size, price-to-book ratio, and promoter holdings. The author came across a negative relationship between grading and the level of underpricing and a positive correlation between the subscription rate and underpricing. The second facet from the above study examined the post-listing market-adjusted performance of graded IPOs at a period of 1 month. IPO performance was considered as a function of the IPO grade, firm age, issue size, price-to-book ratio, and holdings not held by the promoter. Results from the study uncover an inverse relationship between IPO grade and performance by the end of 1-month. The above study finds that (1) a higher-grade IPO brings about lower underpricing with much less 'money left on the table,' and, (2) that higher graded IPOs performed better over the short period of 30-days. The author does not state if effects of certification are the reason that explains higher underpricing for lower grade IPOs or if underwriters underprice issues to increase subscription rates, especially when it comes to lower grade IPOs. The limitations in this study are the lack of any Grade 5 IPOs as well as the absence of a longer-term performance test.

Two of the objectives in a study by Deb and Marisetty (2010) discussed whether certification effects appear to lower underpricing for higher graded IPOs, and, if the long-run performance of higher-graded IPOs is much better than lower graded IPOs. The study sample consisted of 48 graded IPOs listed in India during the period 2006-2009. The authors conclude that there is a negative correlation between the IPO grade and initial return. Regarding the longrun performance of graded IPOs, the authors discover that the long-run performance over 1-year using the buy-and-hold measurement method amongst graded IPOs is not considerably different. In summary, the above study finds that (1) effects of certification appear with lower grade IPOs underpriced more than higher grade IPOs, and (2) the long-run performance test finds that the performance of graded IPOs is the same irrespective of the IPO grade. Three limitations in this study are the small sample size; the initial returns are not adjusted for the market movement in the corresponding period, and, that the long-run performance is analyzed only for one year.

Khurshed et al. (2014) examined 354 bookbuilt IPOs that consisted of 150 graded IPOs listed on the Bombay Stock Exchange (BSE) and National Stock Exchange (NSE) between 1999 and 2011. One of the objectives consisted of testing the efficiency of graded IPOs by monitoring the market-adjusted underpricing. A multivariate regression model was developed to test underpricing as a function of the assigned grade, issue size besides other independent variables. Based on the results of the model, the authors confirmed that the effects of certification are not visible and that IPO grading has no impact on underpricing.

One of the objectives in the study by Jacob and Agarwalla (2015) concentrated on testing the certification hypothesis by examining underpricing with a sample of 182 graded issues listed in India during the six years between October 2005 and September 2011. The authors use marketadjusted returns and do not find any substantial impact of IPO grading on underpricing. One 
limitation of the above study is the small sample of three grade 5 IPOs, that makes the findings unreliable.

Sahoo (2016) examined the certification hypothesis and discussed the effectiveness of IPO grading on underpricing using a sample of 116 graded IPOs listed in India between January 2007 and July 2011. The effect of variables including the IPO grade, offer size, firm age, parental group affiliation, investor banking prestige and venture capital participation on the marketadjusted return is examined using the OLS regression test. The results suggested a significant inverse relationship between underpricing and IPO grades.

Dhamija and Arora (2017a) investigate the effects of certification on 197 graded IPOs listed in India between April 2005 and March 2015. Multivariate regression analysis is used to establish the effect of the IPO grade, issue size, market sentiment, and a few more independent variables on the market-adjusted returns. The authors find that the mean and median initial returns for ungraded IPOs are more than that of graded IPOs. Also, the standard deviation of returns was correlated to the IPO grade. Even though the relationship between the excess return and the IPO grade is negative, the relationship is not statistically significant. In summary, the above study finds that (1) grading helps in reducing the information asymmetry, and (2) even though lower-grade issues have higher underpricing then higher-grade issues, the evidence is not statistically definitive.

Dhamija and Arora (2014) examined the three-year long-run performance of 31 graded IPOs listed between May 2007 and January 2010. The authors use cumulative abnormal returns, holding period returns, and wealth relatives to measure the long-run performance. The authors from the above study indicated that the long-run performance of IPOs does not bear any relationship with the grade awarded. The author's results show that (1) there is a substantial variation in the long-run performance of IPOs across different grades, and (2) that lower graded IPOs performed much better than those graded higher over the long term. One limitation of the above study is that the study sample is very small and lacks any Grade 5 IPOs.

Past empirical results suggest that (1) assigning IPO grades does not always reduce underpricing, and (2) the long-run performance of graded IPOs is unpredictable. Barring the study undertaken by Dhamija and Arora (2014), none of the other studies covers the entire period where IPO grading was compulsory, nor do they use multiple measures of long-run performance.

Dhamija and Arora (2017b) examined the initial and after-market performance of $100 \mathrm{SME}$ IPOs listed on the Bombay Stock Market (BSE) and the National Stock Market (NSE) listed between February 2012 and March 2015. The research study employs market-adjusted returns and finds evidence of underpricing of IPOs by SMEs and, that the level of underpricing is discovered to be less than that of IPOs listed on the mainboard stock market in India. However, the authors also note that SME IPOs have a meagre subscription rate which affects the liquidity. Karla and Kansara (2017) examined SME's in India to determine the effects of IPO variables such as issue size, issue price, under-pricing/overpricing, percentage net, etc. on short- and long-term returns. The authors conclude that none of the variables contributed significantly and could not explain returns because of lesser liquidity of SME IPOs in the stock markets. Bhattacharya (2017) examined SME IPOs listed on the BSE between March 2012 and August 2015. The study sample included 106 SME IPOs and was used to study the influence of the issue size, proportion of allocation to market makers and the importance of market timing among other variables on underpricing. Firstly, the authors find a negative relationship between the extent of underpricing and the size of the IPO allocation to the market maker. Secondly, the authors find that market timed SME IPOs tend to have higher initial underpricing. Past literature review in regards to SME IPOs suggests that SME IPOs (1) tend to have lower subscription rates which affect the market liquidity, (2) with lower allocation to market makers results in more underpricing, and (3) market timed IPOs tend to have higher initial underpricing. These are the shortcomings with including SME IPOs in this study and hence are excluded from the sample in this study. 
Cai, Ramchand and Warga (2004) evaluate the signaling hypothesis to establish if secondary equity offerings (SEO) experience lower underpricing compared to other equity IPOs. Their study sample consisted of 91 equity IPOs that have a previous public debt outstanding at the time of the equity IPO, which are then compared against a sample of all other IPOs. The authors discover that the mean first-day returns (underpricing) of the equity offerings with a prior debt issue is lesser when compared to all the other equity IPOs. Kim and Park (2005) test the issuer's greed hypothesis to determine if firms make opportunistic accounting decisions to increase the prices on secondary offerings at inflated prices. The sample includes 1,040 IPOs of common U.S. stocks issued between 1989 and 2000. Using regression analysis, the authors conclude that SEO firms employ aggressive earnings decisions to increase the offer prices and reducing the degree of underpricing. Past literature review in regards to SEOs suggests that firms raise the offer prices and reduce underpricing. This study excludes all SEOs so as not to influence the average level of underpricing.

\section{Testable hypotheses}

The grade assigned to IPO issues reflects the fundamentals of the issuing firms. Grading of IPOs suggests that it can be considered as a certification mechanism. This method has been embraced by earlier research studies on this subject (Deborah and Marisetty, 2010; Khurshed et al., 2014; Sahoo, 2016). This study examines the listing day and the long-run performance of underpriced graded IPOs in India. The hypothesis to examine the listing day performance and verify the impacts of certification on graded IPOs is

H0: The level of underpricing on the listing day is statistically the same across grade categories.

HA: The level of underpricing on the listing day is statistically different amongst grade categories.

The hypothesis to examine the 3-year long-run performance study to identify if the certification effects of graded IPOs persist over the long-run is

H0: The distribution of BHAR is similar across grade categories at selected intervals during the period of study.

HA: The distribution of BHAR is statistically different among grade categories at selected intervals during the period of study.

\section{Data And methodology}

The study focuses on underpriced graded IPOs listed on the National Stock Exchange (NSE) in India, covering a period of seven fiscal years between FY 2006 until 2013. The study period starts approximately a year before SEBI implemented compulsory IPO grading in India and covers the entire period when IPO grading was compulsory until Feb-2014. Post-Feb-2014, IPO grading was made voluntary for the listing firms by SEBI. The period of mandatory IPO grading provides a much larger sample of graded IPOs for analysis. Access to listing information in addition to historical price data for every IPO issue is obtained from Prime database. This study does not consider SME IPOs (Dhamija and Arora, 2017b; Karla and Kansara, 2017; Bhattacharya 2017) as well as SEOs (Cai et al., 2004; Kim, 2005).

To identify underpriced IPOs and examine the listing day performance, 'Marginally Adjusted Abnormal Return on Opening (MAARO)' is calculated for every IPO. For this analysis, the historical NIFTY on the National Stock Exchange in India is used as the market index. MAARO is determined in three steps. In step 1, the raw stock returns (SR), which is the percentage difference between the offer price and the closing price (on the first listing day) is calculated for every IPO. In step 2, the NIFTY index returns (MR) is calculated using closing index values on the offer and the listing date for each IPO. In step 3, the difference between returns obtained from step 1 and step 2 is calculated to adjust the raw returns for any volatility in 
the markets between the offer date and the listing date. Towards achieving results on nonnormalized data, MAARO is transformed using Johnson transformations (Johnson, 1949). All results on normalized data are back-transformed for clarity in the results and discussion section. MAARO is calculated as follows:

$$
M A A R O=\left[\left(\frac{1+S_{R}}{1+M_{R}}\right)-1\right] * 100
$$

IPOs are validated using a one-way ANOVA test on the normalized MAARO. Using Equation 1 , the sample of underpriced graded IPOs contains 38 IPOs in Grade $1 \& 2$ (hereafter lower grade category), 34 IPOs in Grade 3 (hereafter average grade category) and 32 IPOs in Grade $4 \& 5$ (hereafter higher-grade category). For the long-run performance study of underpriced graded IPOs, the sample includes 35, 33, and 32 lower, average, and higher-grade IPOs, respectively.

Trading history for every underpriced graded IPOs is analyzed from the date of listing for three years (36 months of 21 consecutive trading days) to examine their long-run price performance. Some IPOs from the listing day study are excluded from the long-run study because of insufficient trading history or interruptions in trading for the IPO issue. For examining the long-run performance between underpriced graded IPO categories, this study evaluates longrun abnormal performance as measured by the buy and hold abnormal return (BHAR) for each IPO and afterwards, the Average BHAR (ABHAR). BHAR approach is frequently the most-cited method for studies on long-run performance in research papers, for instance, Lyon, Barber, and Tsai (1999); Fama (1998). ABHAR is computed to examine the long-term performance for three years (36 months of 21 consecutive trading days) from the listing date. BHAR approach expects that an amount of money is passively invested on the first day and held for a specified period. This return is then corrected using returns on the market index (NIFTY) to get a market-adjusted BHAR. Market-adjusted BHAR is computed with reference to the listing price. Market-adjusted BHAR is calculated as:

$$
\text { BHARiT }=\prod_{t=1}^{T}\left(1+R_{i t}\right)-\prod_{t=1}^{T}\left(1+R_{m t}\right)
$$

where Rit is the return of the individual IPO stock i on day t from the offer day; Rmt is the market index return for the corresponding period. The Average BHAR (ABHAR) for the entire sample is also calculated to find out the overall performance of the portfolio of IPOs for a specific period for the sample of size N. This is computed as:

$$
A B H A R=\frac{1}{N} \sum_{i=1}^{N} B H A R_{i T}
$$

A positive ABHAR for a certain period is taken as better performance for the IPOs compared to the benchmark return for the same period. A standard t-test is prone to cross-sectional correlation and volatility changes. A further issue occurs when computing t-statistics for skewed distributions. The skewness adjusted t-test, introduced by Hall (1992), remedies the crosssectional t-test for skewed abnormal return distributions. This study implements cross-sectional t-test since it applies to average buy-and-hold abnormal returns. The long-run performance test across grade categories is verified using the Kruskal-Wallis test.

This study also uses wealth relative (WR) as another measure to examine the long-run performance of IPOs at a point in time. This method was used by Ritter (1991) and further by Levis (1993). A WR of greater than one suggests the better performance of IPOs over the market index, while a value of lower than one indicates an underperformance of IPOs. Levis (1993) define wealth relative as: 


$$
W R_{i t}=\frac{1+\frac{1}{N} \sum_{i=1}^{N} R_{i t}}{1+\frac{1}{N} \sum_{i=1}^{N} R_{m t}}
$$

where Rit is the return of the individual IPO stock i on day t from the offer day; Rmt is the market index return for the corresponding period. The wealth relatives are computed at specific intervals from the offer price in this study. The total size of IPOs in the portfolio for discussion is represented by $\mathrm{N}$. The technique for the computation of WR is consistent with Ritter (1991).

\section{Results AND DisCussions}

Table I summarizes the average MAARO of underpriced graded IPOs. For the majority of the listed years, a lower average MAARO in higher grade IPOs is observed when compared to lower and average grade category IPOs.

\begin{tabular}{|c|c|c|c|c|c|c|}
\hline \multicolumn{7}{|c|}{ Table I: Graded Underpriced IPO Issues (FY 2006-2013) } \\
\hline Fiscal Year & \multicolumn{3}{|c|}{ Underpriced IPOs } & \multicolumn{3}{c|}{ Average MAARO (\%) } \\
\hline & Grade $1 \& 2$ & Grade 3 & Grade $4 \& 5$ & Grade $1 \& 2$ & Grade 3 & Grade 4 \& 5 \\
\hline $2006-2007$ & 2 & 1 & 0 & 83.14 & 17.06 & \\
\hline $2007-2008$ & 6 & 9 & 7 & 13.95 & 37.31 & 15.72 \\
\hline $2008-2009$ & 6 & 5 & 0 & 46.64 & 6.89 & \\
\hline $2009-2010$ & 6 & 5 & 6 & 26.11 & 17.04 & 8.36 \\
\hline $2010-2011$ & 10 & 10 & 13 & 42.46 & 16.81 & 11.95 \\
\hline $2011-2012$ & 7 & 3 & 3 & 53.25 & 29.87 & 3.50 \\
\hline $2012-2013$ & 1 & 1 & 2 & 1.20 & 11.25 & 7.60 \\
\hline $2013-2014$ & 0 & 0 & 1 & & & 20.08 \\
\hline \multicolumn{7}{|c|}{ Source: MAARO computed from Equation (1) } \\
\hline
\end{tabular}

Figure I depict the extent of underpricing across financial years for each of the grade categories.

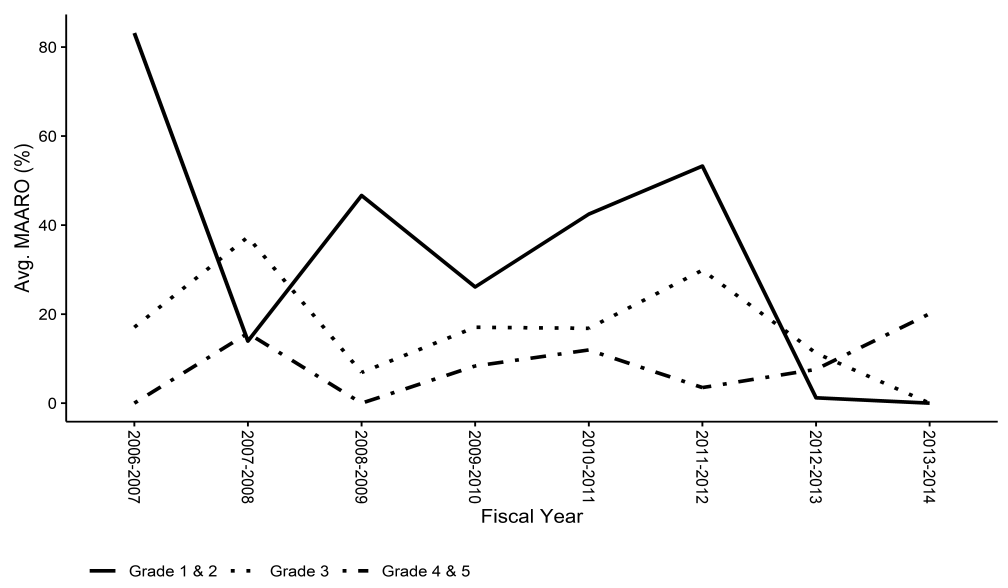

Figure I: Underpriced Graded IPOs Average MAARO (FY 2006-2013). (Source: Average MAARO from Table I) 


\begin{tabular}{|c|c|c|c|c|c|c|c|}
\hline \multicolumn{6}{|c|}{ Table II: Results of one-way ANOVA test using MAARO - Graded IPOs } \\
\hline Grade & IPOs & Mean & Std. Dev. & Mean & Sig. & \multicolumn{2}{|c|}{ Confidence Interval } \\
\hline Classification & & & & Difference & & Lower Bound & Upper Bound \\
\hline Grade 1 \& 2 & 38 & 34.44 & 75.42 & & & & \\
\hline Grade 3 & 33 & 17.70 & 74.61 & 16.74 & 0.019 & 31.10 & 85.47 \\
\hline Grade 4 \& 5 & 32 & 10.66 & 62.70 & 23.78 & 0.000 & 47.63 & 120.55 \\
\hline \multicolumn{7}{|c|}{ Source: Author Computed } \\
\hline
\end{tabular}

The results of the one-way ANOVA test to establish differences in normalized MAARO amongst grade categories is shown in Table II. All IPOs were categorized into three categories: lower-grade category IPOs $(\mathrm{n}=38)$ include Grade 1 and 2 underpriced IPOs, average grade category IPOs $(\mathrm{n}=34)$ include all Grade 3 underpriced IPOs, and finally, higher grade category IPOs $(\mathrm{n}=32)$ include Grade 4 and 5 underpriced IPOs. There was a presence of one outlier for a Grade 3 IPO which was ignored for further analysis. Variances were homogeneous, as assessed by Levene's test for equality of variances $(\mathrm{p}=0.353)$. Data are presented as mean \pm standard deviation. MAARO decreased from lower grade IPOs $(\mathrm{n}=38,34.44 \pm 75.43)$, to average grade IPOs $(n=33,17.70 \pm 74.61)$, to higher grade IPOs $(n=32,10.66 \pm 62.70)$, in that order. Normalized MAARO was statistically different for different levels of capitalization, $\mathrm{F}(2,100)=10.954, \mathrm{p}<.0005, \omega 2=0.162$.

Tukey-Kramer post hoc analysis (results used if homogeneity of variances assumption is not violated) revealed that MAARO decreased from $34.44 \pm 75.42$ for lower grade IPOs to $17.70 \pm 74.61$ for average grade IPOs, a decrease of 16.74 (95\% CI, 31.10 to 85.47), which was statistically significant $(\mathrm{p}=0.019)$. MAARO decreased from $34.44 \pm 75.42$ for lower grade IPOs to $10.66 \pm 62.70$ for higher grade IPOs, a decrease of 23.78 (95\% CI, 47.63 to 120.55), which was statistically significant $(\mathrm{p}=0.000)$. This investigation on listing day finds that underpricing reduces with increasing grades.

The null hypothesis is rejected since the extent of underpricing is statistically significant between lower and average grade IPOs in addition to between lower and higher-grade IPOs. Although there is no statistically significant difference between IPOs with Grade 3 and Grade $4 \& 5$, our results establish that underpricing decreases with increasing grades. This outcome indicates that grading of IPOs succeeds as a certifying mechanism with firm IPOs having designated higher grades leaving "less money on the table" when compared to lower grade IPOs. The results of the listing day performance resemble previous other findings in India for instance, Poudyal (2008); Deb and Marisetty (2010); Sahoo (2016) but are different from other studies in India for example, Khurshed et al. (2014); Jacob and Agarwalla (2015); Dhamija and Arora (2017a).

The next facet of the study pertains to the long-run performance of graded underpriced IPOs. The sample consists of 35, 33, and 32 lower, average, and higher graded category IPOs, respectively. Tables III lists the tskew and wealth relatives for selected months of the relevant IPO groups.

\begin{tabular}{|c|c|c|c|c|c|c|c|c|c|c|c|c|}
\hline \multirow[b]{2}{*}{ Month } & \multicolumn{4}{|c|}{ Grade $1 \& 2$ Issues (35 IP Os) } & \multicolumn{4}{|c|}{ Grade 3 Issues (33 IPOs) } & \multicolumn{4}{|c|}{ Grade $4 \& 5$ Issues (32 IPOs) } \\
\hline & ABHAR & t-skew & Sig. & W R & ABHAR & t-skew & Sig. & W R & ABHAR & t-skew & Sig. & W R \\
\hline 1 & $-9.31 \%$ & -1.3456 & & 0.885 & $-5.92 \%$ & -1.1704 & & 0.956 & $-0.21 \%$ & -0.1587 & & 0.837 \\
\hline 6 & $-0.54 \%$ & 0.0275 & & 0.883 & $-1.22 \%$ & -0.1023 & & 0.959 & $-6.81 \%$ & -1.401 & & 0.816 \\
\hline 12 & $-5.50 \%$ & -0.2868 & & 0.929 & $-13.99 \%$ & -1.6137 & & 0.871 & $-9.84 \%$ & -1.5673 & & 0.79 \\
\hline 18 & $-31.40 \%$ & -1.9374 & * & 0.715 & $-11.39 \%$ & -0.6102 & & 0.871 & $-11.94 \%$ & -1.938 & * & 0.757 \\
\hline 24 & $-48.89 \%$ & -1.7487 & $*$ & 0.483 & $-9.12 \%$ & -0.4654 & & 0.882 & $-17.34 \%$ & -2.8773 & $* * *$ & 0.697 \\
\hline 30 & $-55.81 \%$ & -2.3226 & $* *$ & 0.422 & $-11.14 \%$ & -0.5113 & & 0.901 & $-21.62 \%$ & -2.9418 & $* * *$ & 0.658 \\
\hline 36 & $-61.82 \%$ & -1.706 & $*$ & 0.356 & $-24.65 \%$ & -1.1894 & & 0.789 & $-30.37 \%$ & -3.2045 & $* * *$ & 0.592 \\
\hline
\end{tabular}


Lower-grade IPOs deliver statistically abnormal negative returns in four periods of the seven periods examined, with one month being statistically significant at 5 percent. Average grade IPOs do not demonstrate any statistically significant abnormal returns for the selected periods. Higher grade IPOs deliver statistically significant abnormal returns in 4 of the seven periods, with three periods being statistically significant at 1 percent. WR is $0.356,0.789$, and 0.592 by the end of 3-years for lower, average, and higher-grade IPOs, which signifies poor performance vis-à-vis the market performance.

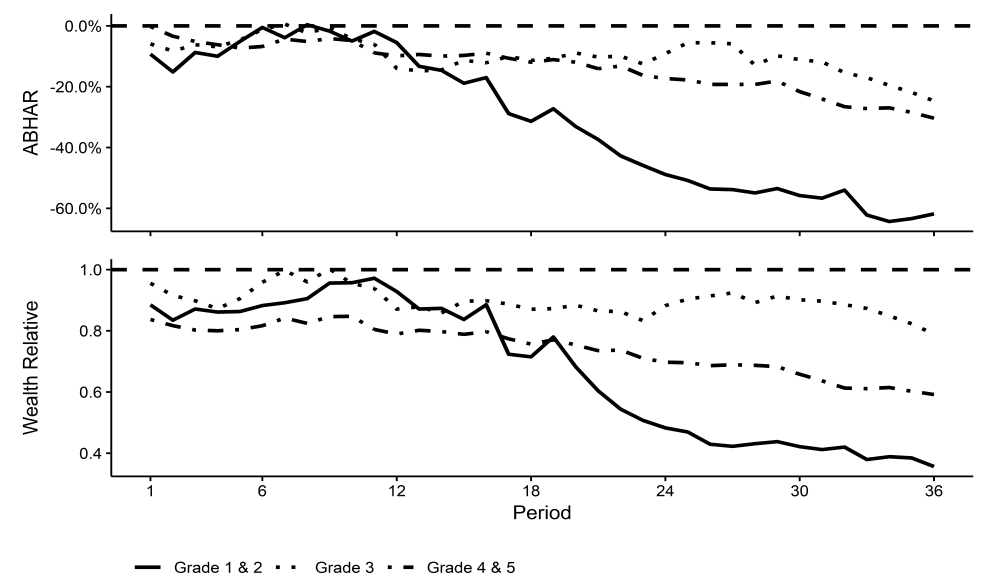

Figure II: Long-Run performance of Graded Underpriced IPOs. (Source: From Table III)

Figure II illustrates the long-run performance of graded underpriced IPOs. None of the graded IPOs delivered a positive abnormal return for any one of the months throughout the long-run performance study of three years.

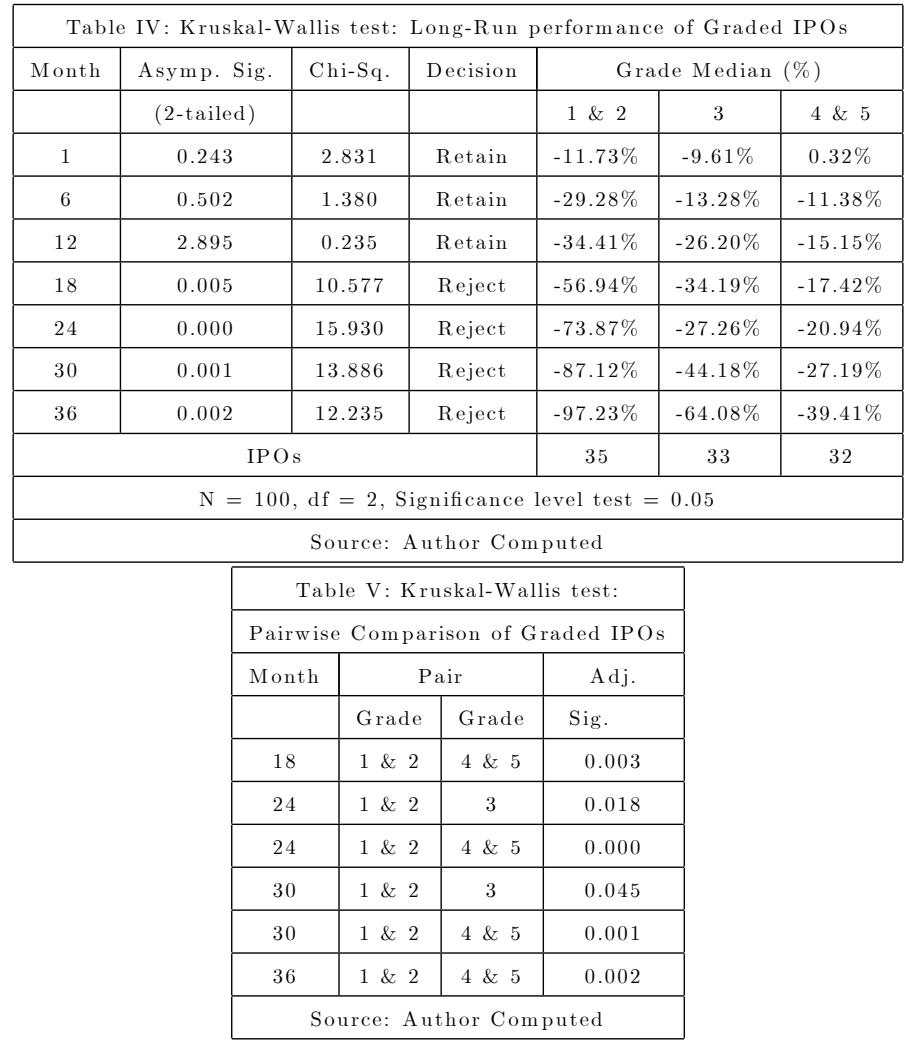


Table IV details the outcomes of the BHAR comparison between grades, whereas Table V provides the outcomes of the grade pairwise comparison. A Kruskal-Wallis test was performed at the $95 \%$ significance level to ascertain if the distribution of BHAR was the same across grade categories at specific intervals. Results suggest that the null hypothesis can be rejected for the 18th, 24th, 30th, and the 36th month. Subsequently, pairwise comparisons were executed using the Dunn (1964) procedure. A Bonferroni correction for multiple comparisons was made with statistical significance accepted at the $\mathrm{p}<.017$ significance level. As seen in Table V, there are statistically significant pairwise comparisons for the 18th, 24th, 30th, and the 36th month. The median performance of underpriced graded IPOs varies significantly beyond the 18th month. Lower, average and higher-grade IPOs deliver returns of $-61.82 \%,-24.65 \%$ and $-30.37 \%$ respectively in the 36 th month. This study rejects the null hypothesis based upon the long-run performance for the 18th, 24th, 30th, and the 36th month.ABHAR is negative for all IPO grade categories towards the completion of three years. Also, the results are mixed since average grade IPOs perform better than higher grade IPOs with lower grade IPOs performing worst. This finding is different from that of Dhamija and Arora (2014) who find that lower graded IPOs perform better and also with that of Deb and Marisetty (2010) who find that long-run performance of graded IPOs is the same regardless of the IPO grade. Our results are mixed since average grade category IPOs perform better than lower or higher-grade categories. The unfavourable returns for all grade categories suggests that (1) the long-run performance of IPOs is hugely challenging to anticipate even for higher graded IPOs since market conditions tend to vary; sometimes drastically over the long term, (2) that the impacts of certification do not persist over the long-run with all graded IPO categories providing negative returns over the period of study, and (3) price corrections are extreme over the long run with lower grade IPOs.

\section{Summary and CONCLUSion}

This study focuses on examining the listing day performance of underpriced graded IPO issues and the effect of IPO grades on the long-run performance at chosen intervals. All graded IPOs were listed in India between FY 2006 and 2013. Our sample consists of 104 underpriced graded IPOs for the listing day performance study and 100 underpriced graded IPOs for the long-run performance study.

The study on listing day performance finds evidence of certification effects across graded IPOs. Lower-grade IPOs display the highest level of underpricing, followed by IPOs with average and higher-grade IPOs that exhibit the lowest level of underpricing. IPOs with a higher-grade exhibit fundamental strength of the firm and hence are underpriced the least in contrast to lower grade firms that indicate a low quality of the issuing firm. Higher grade IPOs also indicate the quality of the IPO in the eyes of the investor and hence a lower risk investment rather than poorly graded IPOs where one would expect high returns to compensate the investors for the investment risk. Consequently, underwriters severely underprice lower grade IPO issues to generate interest amongst investors.

Our research study reveals mixed results concerning IPO grades and long-run performance. Lower-grade IPOs performed the worst with average grade IPOs performing the best with respect to decreasing losses over the long-run. ABHAR is negative for all IPO grades towards the end of three years. Lower-grade IPOs experience severe price corrections causing poor longrun performance. Finding causes for the weak long-run performance of underpriced graded IPOs needs more analysis and research. For instance, of the 35 lower grade IPOs, 32 IPOs were issued in hot while three were issued in cold markets. It is conceivable that IPOs perform better when issued in cold markets due to the high quality of the IPO. Of the lower grade 35 IPOs, 32 IPOs were issued using the bookbuilt mechanism while 3 IPOs used the fixed-price mechanism. Another vital point to consider is that the lower grade IPOs have an issue size of less than 2 Billion (Indian Rupees). It is possible that issue size is a reflection of the firm quality.

Our findings have necessary suggestions for issuers, regulators, and investors. There remains to be a significant emphasis outlined by SEBI to enhance disclosure and transparency concerning 
listing firms. Grading of IPOs was an essential step to empower the retail investor in arriving at an informed decision. Trends since the obligatory grading period reveal a decline in the extent of IPO underpricing. Since Feb-2014, IPO grading was made non-obligatory by SEBI since there was no correlation found between the issued grade and its related subscription or the post-listing performance. Nonetheless, it is seen that grading guarantees conformity by listing firms, which helps in reducing underpricing and information asymmetry. Firms should contemplate voluntary grading of their issues since it decreases the extent of underpricing and helps raise more capital. Grading of IPOs has helped in enhancing pricing efficiency, and the regulators should think about offering measures in place of IPO grading in a user-friendly format that highlight the listing firms' valuations.

Our results vary from other literature, probably because of the absence of any SME IPOs or SEOs as well as the inclusion of the entire period of mandatory IPO grading in our sample set. An important constraint of long-run performance studies is that no specific theory has succeeded in explaining the long-run performance of IPOs. Several questions emerge concerning the dissimilarity in findings across the world relating to long-run performance. Likely reasons for this disparity suggest the different time-periods of study and the methodology used to calculate long-run returns. Moreover, over-time, market qualities change drastically shifting from a bull to a bear phase, shifts in the macroeconomic scenario, etc. A future study would call for evaluating the impact of such shifts on the long-run performance of IPOs.

\section{REFERENCES}

[1] Allen, F., \& Faulhaber, G. R. (1989). Signalling by underpricing in the IPO market. Journal of Financial Economics, 23(2), 303-323.

[2] Barry, C. B., Muscarella, C. J., Peavy Iii, J. W., \& Vetsuypens, M. R. (1990). The role of venture capital in the creation of public companies: Evidence from the going-public process. Journal of Financial Economics, $27(2), 447-471$.

[3] Beatty, R. P., \& Ritter, J. R. (1986). Investment banking, reputation, and the underpricing of initial public offerings. Journal of Financial Economics, 15(1-2), 213-232.

[4] Bhattacharya, A. (2017). Innovations in new venture financing: Evidence from Indian SME IPOs. Global Finance Journal, 34(C), 72-88.

[5] Carter, R. B., Dark, F. H., \& Singh, A. K. (1998). Underwriter reputation, initial returns, and the long-run performance of IPO stocks. The Journal of Finance, 53(1), 285-311.

[6] Cai, N., Ramchand, L., \& Warga, A. (2004). The pricing of equity IPOs that follow public debt offerings. Financial Management, 5-26.

[7] Chan, K. C., \& Lo, Y. L. (2011). Credit ratings and long-term IPO performance. Journal of Economics and Finance, 35(4), 473-483.

[8] Chemmanur, T. J. (1993). The pricing of initial public offerings: A dynamic model with information production. The Journal of Finance, 48(1), 285-304.

[9] Chemmanur, T. J., \& Fulghieri, P. (1994). Investment bank reputation, information production, and financial intermediation. The Journal of Finance, 49(1), 57-79.

[10] Deb, S. S., \& Marisetty, V. B. (2010). Information content of IPO grading. Journal of Banking \& Finance, 34(9), 2294-2305.

[11] Dhamija, S., \& Arora, R. K. (2014). The long-run performance of graded IPOs in the Indian capital market. Global Business Review, 15(2), 317-337.

[12] Dhamija, S., \& Arora, R. K. (2017a). Impact of quality certification on IPO underpricing: Evidence from India. Global Business Review, 18(2), 428-444.

[13] Dhamija, S., \& Arora, R. K. (2017b). Initial and After-market Performance of SME IPOs in India. Global Business Review, 18(6), 1536-1551.

[14] Dunn, O. J. (1964). Multiple comparisons using rank sums. Technometrics, 6(3), 241-252.

[15] Fama, E. F. (1998). Market efficiency, long-term returns, and behavioural finance. Journal of Financial Economics, 49(3), 283-306.

[16] Grinblatt, M., \& Hwang, C. Y. (1989). Signalling and the pricing of new issues. The Journal of Finance, 44(2), 393-420.

[17] Hall, P. (1992). On the removal of skewness by transformation. Journal of the Royal Statistical Society. Series B (Methodological), 54, 221-228.

[18] Ibbotson, R. G., Sindelar, J. L., \& Ritter, J. R. (1994). The market's problems with the pricing of initial public offerings. Journal of applied corporate finance, 7(1), 66-74. 
[19] Jacob, J., \& Agarwalla, S. K. (2015). Mandatory IPO grading: does it help pricing efficiency? Vikalpa, 40(2), 132-144.

[20] Johnson, N. L. (1949). Systems of frequency curves generated by methods of translation. Biometrika, $36(1 / 2), 149-176$.

[21] Kalra, G., \& Kansara, N. (2017). Investigating the myths associated with IPOs of small and medium enterprises: the case of India. International Journal of Indian Culture and Business Management, 14(4), 393-405.

[22] Khurshed, A., Pande, A., Vismara, S., \& Paleari, S. (2014). IPO certification: The role of grading and transparent books. Online paper. Retrieved from https://www.cass.city.ac.uk/__data/assets/pdf_file/0006/86640/Khurshed.pdf.

[23] Kim, Y., \& Park, M. S. (2005). Pricing of seasoned equity offers and earnings management. Journal of Financial and Quantitative analysis, 40(2), 435-463.

[24] Levis, M. (1993). The long-run performance of initial public offerings: The UK experience 1980-1988. Financial Management, 22, 28-41.

[25] Lyon, J. D., Barber, B. M., \& Tsai, C. L. (1999). Improved methods for tests of long-run abnormal stock returns. The Journal of Finance, 54(1), 165-201.

[26] Maksimovic, V., \& Unal, H. (1993). Issue Size Choice and "Underpricing" in Thrift Mutual-to-Stock Conversions. The Journal of Finance, 48(5), 1659-1692.

[27] Megginson, W. L., \& Weiss, K. A. (1991). Venture capitalist certification in initial public offerings. The Journal of Finance, 46(3), 879-903.

[28] Poudyal, S. (2008). Grading Initial Public Offerings (IPOs) in India's Capital Markets A Globally Unique Concept. Indian Institute of Management Ahmedabad - WP No. 2008-12-08.

[29] Ritter, J. R. (1991). The long-run performance of initial public offerings. The Journal of Finance, 46(1), $3-27$.

[30] Sahoo, S. (2016). Signalling by IPO grading: an empirical investigation. Afro-Asian Journal of Finance and Accounting, 6(1), 68-85.

[31] Titman, S., \& Trueman, B. (1986). Information quality and the valuation of new issues. Journal of Accounting and Economics, 8(2), 159-172.

[32] Welch, I. (1989). Seasoned offerings, imitation costs, and the underpricing of initial public offerings. The Journal of Finance, 44(2), 421-449. 